\title{
Las otras mitas. Aproximaciones al estudio de la mita de plaza en la jurisdicción de Jujuy, gobernación de Tucumán, siglo XVII/
}

\author{
The other mitas. Approaches to the study \\ of the mita of place in Jujuy, government \\ of Tucumán, XVII century
}

\section{Gabriela Sica}

CONICET/Universidad Nacional de Jujuy, Argentina

El objetivo de este artículo es analizar la conformación de la mita de plaza en la jurisdicción de San Salvador de Jujuy en la gobernación de Tucumán durante el siglo XVII. La mita era una de las instituciones económicas sobre las que reposaba el sistema colonial en los Andes, y permitió garantizar el aporte de trabajo indígena que se volcaba a las obras públicas o diferentes actividades económicas como la minería, agricultura, ganadería, servicios de tambos, etc. Para las comunidades constituía una carga de un porcentaje de sus tributarios que debian abandonar sus propias actividades y en muchos casos trasladarse a considerable distancia, mientras que para distintos sectores como mineros, vecinos sin encomiendas y autoridades era una importante contribución de mano de obra, por esta razón se convirtió en un campo de disputa y tensiones entre los distintos sectores.

Palabras Claves: Mita de plaza; Mano de obra indígena.

The objective of this paper is to analyze the conformation mita system of place in the jurisdiction of San Salvador de Jujuy in the governorate of Tucumán during the seventeenth century. The mita was one of economic institutions on which rested the colonial system in the Andes, and helped to ensure the supply of Indian labor is poured to public works or different economic activities such as mining, agriculture, livestock, dairy services, etc. For indigenous communities was a load of a percentage of tax that they leave their own activities and often travel a considerable distance, while for other sectors such as mining, without encomiendas neighbors and authorities was an important contribution of labor, therefore became a field of dispute and tension between different sectors throughout the seventeenth century.

KeYwords: Mita de plaza; Indian labor. 


\section{Introducción}

En 1613, los caciques Felipe Viltipoco y Marcos Tinta se presentaron ante la audiencia de Charcas. Ellos reclamaban la disminución del número de mitayos que sus comunidades debían enviar a la ciudad de San Salvador de Jujuy. La presentación de los caciques, era parte de una serie de conflictos que se desataron en torno a la reglamentación y funcionamiento de la mita de plaza de Jujuy desde el primer reparto hasta el siglo XVIII. En dichas pugnas se involucraron los sectores que se beneficiaban o perjudicaban con el aporte de mitayos a la ciudad. Caciques, encomenderos, vecinos, mineros y autoridades fueron disputando su acceso a esta mano de obra y generando cambiantes alianzas en relación a las diferentes coyunturas políticas, el desarrollo de distintas actividades económicas y las contiendas jurisdiccionales.

La mita fue una de las instituciones económicas sobre los que reposaba el sistema colonial en América. Basada en la idea de turno de la antigua mit'a incaica, su reformulación durante la colonia creó un sistema de trabajo compulsivo orientado a la minería, la agricultura, la ganadería, la construcción, etc. Aunque tenía antecedentes previos, fue el virrey Toledo quien la institucionalizó durante el siglo XVI para organizar la provisión de mano de obra a las explotaciones minera del altiplano, especialmente Potosí. La mita —en especial la potosina — ha sido estudiada desde diferentes perspectivas, tanto en su contribución de trabajadores a la actividad minera, como en la constitución histórica de una relación de producción. También se ha analizado su efecto en la población indígena, en las migraciones o en las razones de exclusión de determinadas zonas, desde su creación hasta la supresión de la misma. ${ }^{1}$ Estas investigaciones son escasas para otras modalidades de la mita en los Andes y son prácticamente nulos para la gobernación de Tucumán. ${ }^{2}$ Sin embargo, la mita de plaza dentro de la gobernación de Tucumán era un significativo aporte de mano de obra para sostener servicios y construcciones de las ciudades y de sus vecinos en contextos de penurias por las mismas. Y también esta obligación constituía una carga importante para las comunidades que debían destinar parte de sus tributarios para el servicio de particulares y

1 Cobb, 1977; Assadourian, 1979, 223-292; 1989, 3-68; 1985; Bakewell, 1984; Coole, 1985; Abecia, 1988; Tandeter, 1992; González Casanovas, 2000; entre otros.

2 Ruiz Rivera, 1975; Rowe 1957; Sánchez Albornoz, 1988; Whigtman, 1990. 


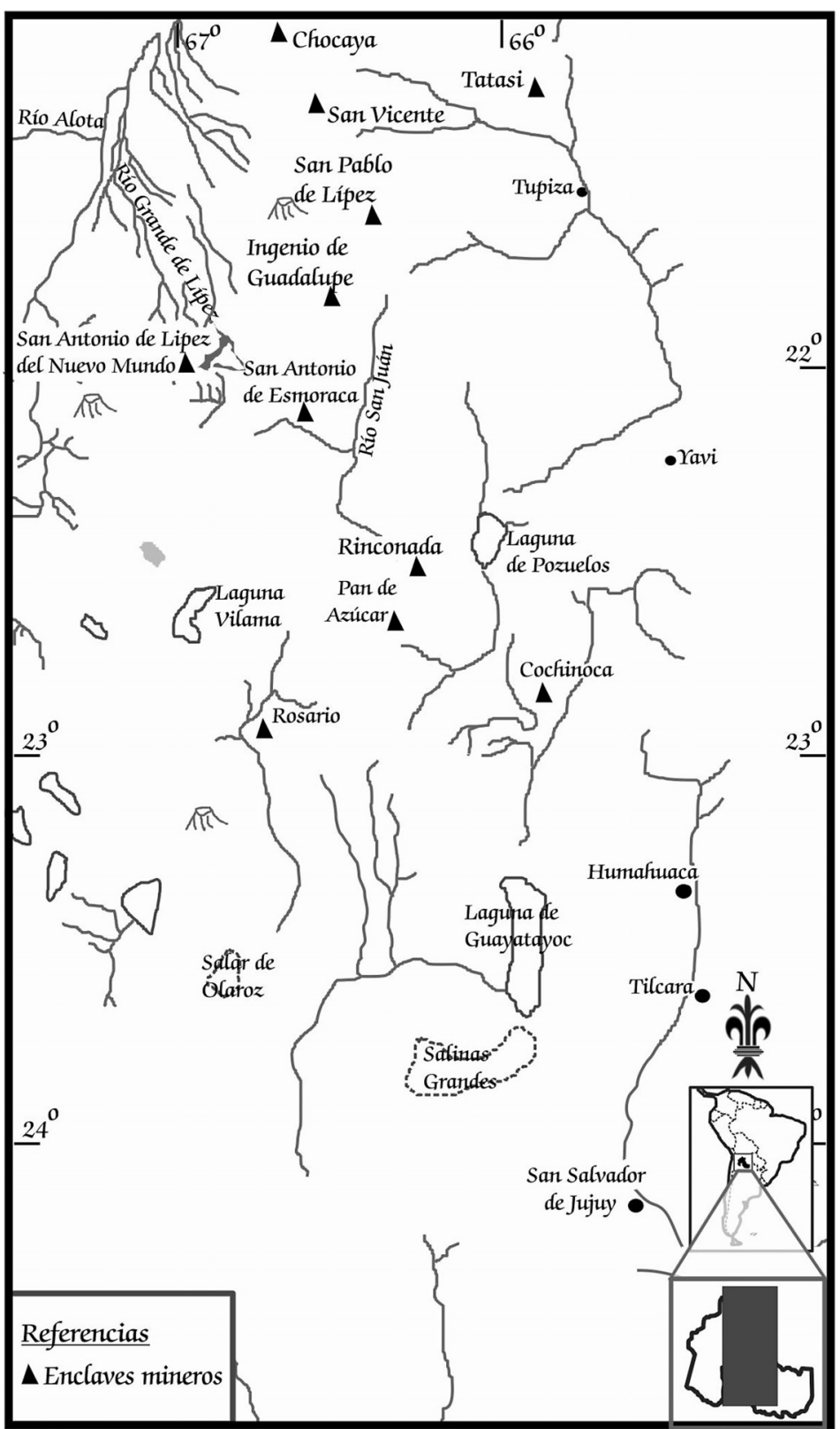

Jurisdicción de San Salvador de Jujuy y zonas mineras 
obras públicas juntos con las derivadas de las cargas del tributo al encomendero.

En este artículo nos proponemos realizar una primera aproximación al estudio de la mita de plaza en una de las jurisdicciones de la gobernación de Tucumán durante el siglo XVII. Se plantea abordar la manera en que fue institucionalizado el sistema; las autoridades encargadas de su funcionamiento; las tareas a que se destinaban los contingentes de la mita y los conflictos que afloraron entre los diferentes sectores por la mano de obra mitaya.

La ciudad de San Salvador de Jujuy — después de dos intentos de instalación previa - fue organizada en 1593 en la ruta que unía los centros mineros con la gobernación de Tucumán. Una parte de sus habitantes prehispánicos se repartió en encomienda antes de la última fundación. Estas encomiendas estuvieron en manos de vecinos de La Plata, Tarija y Salta según avanzaba la ocupación española hacia el sur. La jurisdicción lindaba con áreas mineras en expansión como la de Lipez y Chichas (jurisdicción de Charcas). ${ }^{3}$

Después de creada la ciudad y tras la definitiva pacificación, la población indígena quedó distribuida en varias encomiendas, de las cuales ocho se mantuvieron hasta finales del siglo XVIII y principios del XIX. ${ }^{4} \mathrm{La}$ población encomendada fue reducida en pueblos de indios construidos a instancias de sus encomenderos. El tributo era pagado con servicios personales y a veces en efectivo - pese a que las Ordenanzas de Alfaro lo habían tasado en dinero y en el caso de Jujuy contemplaban su conmutación en productos específicos de la región- . $^{5}$

Estas encomiendas no reunían una gran cantidad de tributarios, en comparación con las de los Andes Centrales y las de la audiencia de Charcas. Por ello la mita de plaza movilizaba contingentes de menor magnitud respecto a los de otras áreas. Sin embargo, por pocos que fueran resultaba un preciado aporte de mano de obra temporal para las instituciones y vecinos que no hubieran obtenido encomiendas en la jurisdicción.

3 Zanolli, 2005; Palomeque, 2006; Sica, 2006.

4 Tal como era común en el resto de la gobernación de Tucumán, concluida la tercera vida de los encomenderos las mismas volvían a reasignarse a nuevos encomenderos. Durante el siglo XVII las encomiendas de Jujuy estuvieron bajo el dominio de un particular. Recién en la segunda mitad del siglo XVIII algunas de ellas pasaron a cajas reales, aunque otras se mantuvieron bajo el sistema de encomienda hasta el siglo XIX.

5 Levillier, $1918,319$. 
Es difícil conocer exhaustivamente la cantidad y evolución de la población indígena colonial en Tucumán y Jujuy durante los siglos XVI y XVII. Aquí solo se realizaron unos pocos recuentos generales y algunas estimaciones o padrones incompletos. Hacia fines del 1500, el gobernador Ramírez de Velazco ponderaba un total de 56.000 tributarios (hombres entre los 18 y los 50 años), de los cuales 3.000 vivían en la jurisdicción de Jujuy y sumados a sus familias permitían estimar un total de unas 15.000 personas en la jurisdicción. ${ }^{6}$

En 1607 se efectuó el padrón del gobernador Alonso de Ribera. Según esta fuente, la jurisdicción de la ciudad de Jujuy tenía unos 490 tributarios distribuidos en 8 encomiendas. ${ }^{7}$ En la segunda mitad del siglo XVII, hubo dos recuentos generales para toda la gobernación de Tucumán: en el primero de 1673 se contabilizaron en Jujuy 463 tributarios y en el segundo (1692-1694) durante la visita a las encomiendas del Tucumán, ${ }^{8}$ el oidor Luján de Vargas registró en Jujuy 191 tributarios. $^{9}$ Aparte de ellos contamos con algunos padrones, como los realizados con los cambios de investidura y unos pocos registros parroquiales. Todas estas cifras se pueden ver en el Cuadro n. ${ }^{\circ} 1$.

Sobre esta población indígena se organizó el sistema de mita de la jurisdicción de Jujuy, desde los últimos años del siglo XVI. La reglamentación de la misma estuvo en manos de los gobernadores de Tucumán y de un visitador de la audiencia de Charcas y su implementación fue objeto de pleitos y enfrentamientos a lo largo del XVII.

6 Carta citada en A. M. Lorandi, 1988, 253. Esta cifra la calculaba el gobernador Ramírez de Velasco considerando que el grupo familiar de cada tributario era de 5 personas. Véase también: Lorandi, 1992, 147; Rubio Durán, 1998, 38.

7 Rubio Durán, 1998, 39.

8 Las cifras de 1673 fueron publicadas en: Ravignani, 1934, II, 295-305. Véase también: González Rodríguez, 1984, 199-211. Sobre la visita del oidor Antonio Luján de Vargas a las encomiendas de la gobernación de Tucumán véase: Doucet, 1980, 123-154. Archivo Nacional de Bolivia (ANB) 1694- 22. Los recuentos de La Rioja y Jujuy están transcritos y publicados en R. Boixadós y C. Zanolli, 2003, 67-312.

9 Sin embargo, las cifras de esta última visita se encuentran disminuidas si se comparan con otros recuentos contemporáneos de las mismas encomiendas. Una de las razones de esta disminución se debió, según varios autores, a la forma de empadronar del visitador, ya que prefirió concentrar a los tributarios de las diferentes encomiendas con sus caciques y encomenderos en un sólo lugar, en vez de recorrer los diferentes pueblos de la jurisdicción, acción que favoreció el subregistro. Boixadós y Zanolli, 2003, 279-312. 
CUADRO N. ${ }^{\circ} 1$

ESTIMACIONES SOBRE EL NÚMERO DE TRIBUTARIOS DE JUJUY. SIGLO XVII

\begin{tabular}{|c|c|c|c|c|c|c|c|}
\hline Años & $\begin{array}{c}\text { Omaguaca } \\
\text { Uquia }\end{array}$ & Ocloya & Paipaya & $\begin{array}{c}\text { Casabindo } \\
\text { y Cochinoca }\end{array}$ & Yala & Purmamarca & $\begin{array}{l}\text { Tilcara } \\
\text { y Ossas }\end{array}$ \\
\hline 1584 & & & $100 ?$ & & & & \\
\hline 1602 & & & & & 17 & & \\
\hline $1620 / 35$ & $122^{10}$ & & 29 & & & & 109 \\
\hline 1640 & & & & & 31 & & \\
\hline 1647 & & & & 77 & & & \\
\hline 1651 & & & 29 & & & & \\
\hline 1654 & & & & 75 & & & \\
\hline 1669 & & & 26 & & & & 25 \\
\hline 1670 & & 100 & & & & & 20 \\
\hline 1673 & 80 & 183 & 28 & 109 & 12 & 17 & 26 \\
\hline 1675 & & 100 & & 158 & & & \\
\hline 1683 & & 40 & & & & & \\
\hline 1688 & & & & 130 & & & \\
\hline 1694 & 37 & 34 & 8 & 84 & 6 & 5 & 15 \\
\hline 1699 & & & & 108 & & & \\
\hline
\end{tabular}

Fuentes: Archivo de Tribunales de Jujuy (ATJ) 1640-237; ATJ, 1683-591; ATJ, 1629-89; ATJ, 1651316; ANB, ec 1607.5, Archivo General de Indias (AGI), 1699, Buenos Aires 8: 8-11; AGI, 1670, Charcas 103, N 13; ANB, ec 1631- 39; Ravignani, II (Buenos Aires) 1934; González Rodríguez, 1984. Palomeque y Tedesco, 1999; Madrazo, 1982; Boixadós y Zanolli, 2003; Archivo General de la Nación (AGN) Sala IX 1716. 9-2-3.

\section{Reglamentando la mita de plaza en Jujuy}

El intento más temprano de instituir la mita de plaza aparece en un pedido elevado por el procurador de la ciudad de Jujuy al gobernador de Tucumán en 1595. En ese momento, el gobernador Mercado de Peñaloza había visitado la ciudad y participado activamente en la pacificación definitiva de la jurisdicción, junto con el fundador Francisco de Argañaraz. Esta acción los llevo a realizar una serie de incursiones en las cuales apresaron a varios caciques principales de la jurisdicción. ${ }^{11}$ Ellos representaban a la

10 Incluye el pueblo de San Rafael de Sococha pueblo de la encomienda de Omaguaca que estaba ubicado en la jurisdicción de la Audiencia de Charcas.

11 ATJ 1595- 23, 1v.- 2. 
mayor parte de la población indígena comprendida en los límites de la nueva jurisdicción. Sin embargo algunos de estos grupos formaban parte de encomiendas muy tempranas, entregadas a vecinos de Charcas, Tarija y Salta. ${ }^{12}$

Producto de esta visita a Jujuy, el gobernador Mercado de Peñaloza conocía muy bien la frustración que significaba para los habitantes de Jujuy descubrir que una vez apresados los caciques aparecían sus encomenderos a tomar posesión de ellas. Doble frustración porque muchos de estos encomenderos vivían en ciudades cercanas. ${ }^{13}$ Por ello decidió otorgar a los vecinos de Jujuy algún tipo de acceso a la mano de obra reglamentando la mita de plaza de la ciudad y de manera provisoria los distribuyó:

Vengan los indios siguientes del pueblo de Yala indios del cacique Don alonso Ossa que esta tres leguas de esta Ciudad. Vengan sinco indios del pueblo de tilian, que esta apartado de esta Ciudad seis leguas, vengan otros cincos indios del Pueblo de Purmamarca que esta apartado de esta ciudad ocho leguas, vaian sinco indios de los indios churumattas que agora de presente estan apartados de esta ciudad vengan ocho indios de repartimiento de umaguaca que esta apartado de esta Ciudad, vengan doze indios de los repartimientos de Casabindo y Cochinoca que estan apartados de esta ciudad veinte y sinco leguas vengan ocho indios que por todos son cincuenta y seis. ${ }^{14}$

Lo interesante de este reparto es que se realizó sobre grupos recientemente pacificados, y que, en la mayoría de los casos, no estaban todavía reducidos, ni empadronados, razón por la cual no se asignaba un porcentaje de mitayo sobre la cantidad de tributarios de cada pueblo, sino un número fijo de acuerdo al conocimiento y las estimaciones de los vecinos y el gobernador. Por ello, en esta distribución, algunas encomiendas se identificaban con el nombre del cacique, con las distancias en relación a la ciudad y las más importantes son denominadas como repartimientos. ${ }^{15}$ Estas medidas fijaban un turno de mita cuatrimestral, sin especificar en los meses en que debía cumplirse cada turno. Cada 15 días el teniente de gobernador debía vigilar o pagar a cada mitayo un jornal de un real diario, más la comi-

12 Palomeque, 2006, 157; Vergara, 1961, 209.

13 ATJ 1595-23, 1v.- 2.

14 ATJ 1595- 23, 7.

15 Las encomiendas mencionadas como repartimientos eran las más importantes en cuanto el número de tributarios y habían sido parte de encomiendas mayores entregadas por Francisco Pizarro en 1540. En cuanto a las reducciones de los grupos mencionados en la cita sabemos que los pueblos de Santa Ana de Casabindo y Espíritu Santo de Cochinoca fueron fundados después de 1602 (7 años después de este reparto). San Antonio de Humahuaca se levantó en los últimos años del siglo XVI al igual que el de San Ildefonso de Yala. Por su parte, el pueblo de Santa Rosa de Purmamarca se estableció en la segunda mitad del siglo XVII. Los restantes (Churumatas, Tilian y pueblo del cacique Alonso Ossa) estaban en proceso de toma de posesión por parte de sus encomenderos. Sica, 2006, 48-74. 
da. En caso de no haber plata estaba previsto conmutar el pago por animales, maíz o textiles. ${ }^{16}$ La primera reglamentación de Mercado de Peñalosa en Jujuy era parte de su política general de reordenamiento de la población indígena de la gobernación de Tucumán. ${ }^{17}$

Apenas transcurridos seis años de la implantación del sistema, el cabildo de Jujuy tenía serias dificultades para lograr el cumplimiento de la mita. La sala capitular envió a hacer padrones en las chacras cercanas de la ciudad para tener una idea cierta de la cantidad de indios que allí trabajaban y establecer quienes estaban en condiciones de mitar. ${ }^{18} \mathrm{Al}$ mismo tiempo, volvió a recurrir a la autoridad de los gobernadores de Tucumán para confirmar y tratar de que se cumpliera con el envío de los mitayos a la plaza de Jujuy. En dos ocasiones, los gobernadores Martínez de Leiva en 1601 y Barraza Cárdenas en 1602 emitieron dos nuevos Autos en los que reafirmaban el reparto efectuado por su antecesor Mercado de Peñaloza, salvo una pequeña modificación del gobernador Barraza y Cárdenas por la que rebajaba la mita del pueblo de Yala de 5 a 3 mitayos por tener sólo unos 17 tributarios. $^{19}$

En 1611, el oidor Alfaro volvió a reglamentar la mita de plaza como parte de las tareas encargadas por la audiencia de Charcas. El reparto establecido por Alfaro tenía un carácter provisorio ya que - como él reconocía - no estaban terminados los padrones de las distintas encomiendas y por lo tanto era difícil establecer la proporción de tributarios que debía aportar cada uno, reservando el reparto definitivo para al momento de concluir de visita. La nueva distribución fue la siguiente:

Mando que de los pueblos de este distrito se de la mita en el numero y forma siguiente: de los indios cochinoca se den dos indios, de los casabindos se den tres indios, de los Humaguacas se den quatro indios, de los tilcaras se den dos indios, de los pulmamarcas se de un indio, del pueblo de Alonso Tobar se den dos indios, de los osas se den dos indios, de los paipaias se den tres indios y reserba en si a ver si ay mas repartimientos de esta ciudad para de ellos repartir mas indios, item viniendo con los indios ocloyas den por aora dos indios a la dicha ciudad y mita. ${ }^{20}$

En estas asignaciones aparecen integrantes de encomiendas que no se habían considerado antes y desaparecen otras. Tal es caso de los «indios de

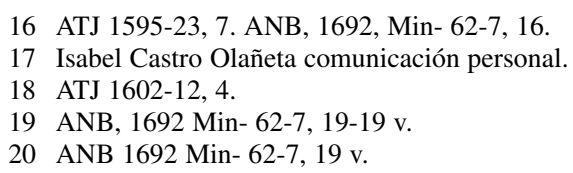


los tilcaras», consignados por primera vez y que pertenecían a la de Francisco de Argañaraz (el fundador de la ciudad) y sus herederos. También se mencionan a los de Paipaya que eran un desprendimiento de la de Churumatas, y para 1611 no tenían todavía sitio fijo de residencia.

Por otra parte ya no se señalaba con obligación de aportar mitayos a los integrantes de dos de ellas. Una de ellas era la de Tilián, quienes habían sido desnaturalizados e instalados en la vecina jurisdicción de Salta. La otra, comprendía a la gente de Churumata, que por esta época había huido de un primer asentamiento y una parte de ellos fue trasladada a una propiedad en Salta, antes de ser reasentados definitivamente en Tarija durante la década de $1630 .{ }^{21}$ Por último, se menciona el pueblo de Alonso de Tobar, que era Yala, en este caso denominado con el nombre de su encomendero.

\section{CuAdro N. ${ }^{\circ} 2$ \\ COMPARACIÓN DEL NÚMERO DE MITAYOS ESTABLECIDOS \\ POR EL GOBERNADOR MERCADO DE PEÑALOZA Y POR EL VISITADOR DE ALFARO}

\begin{tabular}{lcc} 
Encomienda & $\begin{array}{c}N^{\circ} \text { de tributarios } \\
\text { Afectados a la mita } \\
\text { de plaza. } 1596\end{array}$ & $\begin{array}{c}N{ }^{\circ} \text { de tributarios } \\
\text { Afectados a la mita } \\
\text { de plaza. } 1612\end{array}$ \\
\hline Yala & $5^{22}$ & 2 \\
Cacique Ossa & s/d & 2 \\
Paipaya & & 3 \\
Tilián & 5 & \\
Purmamarca & 5 & 1 \\
Churumatas & 5 & 5 \\
Casabindo y Cochinoca & 12 & 2 \\
Ocloya & & 2 \\
Tilcara & & 4 \\
Omaguaca & 8 & 21 \\
No especificados & 8 &
\end{tabular}

Fuente: ANB, 1692 Min- 62-7.

21 Sica, 2006, 31-50.

22 No está consignada la cantidad en el reparto de 1595, pero en 1602 se habla de la reducción de 5 a 3 mitayos.

23 En el auto del gobernador dice que son en total 56 mitayos, sin embargo la suma de los especificados es de 48 mitayos. 
Lo dispuesto por Alfaro reducía considerablemente el número de mitayos aportados: de 46 a 21 (decimos 46 atendiendo a la disminución de 2 mitayos de Yala que había introducido el gobernador Barrasa en 1602). También duplicaba el jornal que debía pagárseles y establecía que la mita se entregaría dividida en dos turnos de cuatro meses entre mayo y diciembre (la estación seca en la región). Para tomar esta decisión, Alfaro había consultado a los caciques de las distintas encomiendas y a los antecedentes insertos en las diferentes ordenanzas de los gobernadores de Tucumán. El drástico reajuste tenía que ver con los objetivos de la visita de Alfaro que intentaba mejorar las condiciones de trabajo de los indígenas y de instaurar el modelo toledano en el Tucumán.

Llama la atención de este nuevo reparto el hecho de que Alfaro rebajó la cuota de mitayos de las encomiendas más populosas, especialmente las de la Puna y la Quebrada de Humahuaca. Por ejemplo, los integrantes de la de Casabindo y Cochinoca debían enviar 5 mitayos, con la reglamentación de Alfaro, en lugar de los 12 establecidos en 1596. La de Omaguaca, pasó de 8 a 4 mitayos. En proporción, la de Paipaya que contaba con un promedio de 20 tributarios debía entregar 3 mitayos. Como dijimos, este Auto de Alfaro se efectuó en enero de 1611, a comienzos de su visita, cuando todavía no estaban realizados los padrones definitivos.

La medida de reducir el número de mitayos y aumentar su salario no fue bien recibida por algunos vecinos de Jujuy, especialmente por aquellos que no habían obtenido una encomienda. En 1612, el propio visitador reglamentó la mita de plaza para toda la gobernación del Tucumán en las cláusulas 46, 47, 48 de sus ordenanzas. De acuerdo con ellas, la mita consistía en el aporte de la sexta parte de los tributarios de cada pueblo, entregados a la ciudad cabecera de la jurisdicción, siempre que no residieran a más de 20 leguas. El reparto de mitayos estaba en manos de un alcalde y un regidor que cada lunes debían adjudicar la mitad de ellos a personas e instituciones que lo requirieran, mientras la otra mitad debía tener libertad de contratarse por su cuenta. Los trabajos para los que se podía utilizar la mano de obra mitaya eran la construcción, las tareas agrícolas y ganaderas, los oficios manuales y servicios de las casas. Se excluían expresamente las labores mineras, con sierras, la doma de equinos, el transporte y acarreo de bienes o personas. ${ }^{24}$

En 1612, cuando las ordenanzas de Alfaro se conocieron, el cabildo nombró como procuradores a Fernando de Toledo Pimentel (vecino de

24 Levillier, 1918, 309-10. 
Santiago del Estero) y a Juan Ochoa de Zarate (encomendero de Omaguaca) para presentarse ante las autoridades y discutir algunas cuestiones pendientes, derivadas de la visita de Alfaro y la aplicación de sus ordenanzas. En sus instrucciones se señalaba la necesidad de garantizar la mita de plaza y la presencia de los mitayos de Casabindo y Cochinoca para Jujuy, así como asegurar que el contingente total debía estar conformado por la sexta parte de los tributarios de cada encomienda. ${ }^{25}$ Sin embargo, sobre este punto, había una fuerte disidencia entre dos bandos. Por un lado, para los encomenderos y comunidades indígenas las normas transitorias de Alfaro eran más convenientes que las nuevas ordenanzas. Por otro, los vecinos que no poseían encomiendas. Para ellos la mita basada en la sexta parte de tributarios prometía elevar las posibilidades de acceder a una mayor cantidad de trabajadores.

La disputa durante esos años fue por sostener la vigencia del auto de Alfaro de enero de 1611 o su nulidad a partir de la promulgación de las ordenanzas de 1612. Esta pugna se tradujo en quejas y pedidos elevados a la real audiencia de Charcas, en la que tuvieron un activo papel los caciques de Tilcara, Casabindo y Cochinoca a través del protector de naturales y el capitán Martín de Ledesma Valderrama. Este último, representaba a un grupo de vecinos sin encomiendas quienes le habían otorgado una carta de poder para presentarse ante la audiencia de Charcas y el virrey a fin de reclamar el cumplimiento de las cláusulas $47,48,49,50$ y 51 de las ordenanzas de $1612 .{ }^{26}$

25 ATJ 1612-38, 228.

26 Archivo Histórico de Jujuy (AHJ)1612, XXI-3-1, 303 v. Martín de Ledesma Valderrama representaba al maese de campo Lope de Bravo de Zamora, a Juan López de Medrano, a Miguel de Heredia, a Antonio Serrano, a Pablo de Argañaraz, a Rodrigo Torres Bohórquez, a Juan Gaitán, a Sebastián de Tobar, a Blas Baca y al capitán Francisco de Morillo. De ellos Bravo de Zamora era un vecino de Santiago del Estero dedicado a la venta de mulas y burros en Jujuy. Pablo Argañaraz era hijo del fundador, aunque la encomienda la había heredado su hermano mayor, poseía una estancia cerca de la ciudad en la cual engordaba ganado para terceros. Juan López de Medrano criaba ganado y negociaba con él. Antonio Serrano se dedicaba al flete de mercancías para terceros pero también trabajaba vendiendo la producción de las haciendas de Juan Ochoa de Zarate, uno de los encomenderos más importante de la época. Juan Gaytan era un vecino que no tenía encomiendas y poseía un par de propiedades en la ciudad y su contorno. Con ellas se dedicaba a la venta de ganado y de diferentes productos como el jabón. También ejercía el oficio de diezmero. En cuanto a Francisco Morillo, tenía una actuación más prominente ya que había comprado el oficio de escribano e intentaba ser encomendero. Desde 1606 llevaba adelante un pleito con otro vecino de Jujuy por una parte de la encomienda de Ocloya. Aparentemente por estos años perdió dicho juicio y necesitaba acceder a mano de obra para el trabajo de sus estancias en Tilquiza. Sobre los dos restantes no encontramos en las fuentes datos sobre sus propiedades u ocupaciones, aunque Miguel de Heredia fue poseedor de estancias en la Puna en la década de 1620 y casas en la ciudad de Jujuy. ATJ 1595-5; ATJ 1596- 6. 
En marzo de 1613, la real audiencia hizo lugar al pedido de Martín Ledesma Valderrama y sus representados, considerando la vigencia de las citadas ordenanzas. Inmediatamente algunos de los caciques de la Quebrada de Humahuaca y la Puna consiguieron, mediante una presentación ante la misma audiencia, disminuir temporalmente el número de mitayos y aumentar el jornal a cobrar. En la presentación de los caciques se apelaba a un nuevo argumento - tomado de la cláusula 48-, por la cual sólo debían mitar las comunidades ubicadas hasta las 20 leguas de distancia de las ciudades cabeceras. Por lo tanto los pueblos de la Quebrada de Humahuaca y de la Puna quedaban fuera de dicha obligación, por la distancia que había entre sus asentamientos y la ciudad de Jujuy. ${ }^{27}$ Este argumento se utilizará reiteradamente en otros pleitos hasta el siglo XVIII. La presentación se completaba con el pedido de que, en el caso de no hacerse lugar a la exención de la mita, se mantuviese el número de mitayos consignados por Alfaro en su auto transitorio y al igual que el pago de un jornal de 2 reales diarios. ${ }^{28}$

Frente al requerimiento de los caciques, la audiencia resolvió dar primera medida de no innovar hasta pronunciarse sobre el fondo de la cuestión. Al poco tiempo dispuso disminuir el contingente de los mitayos a 14 hombres en total (3 menos que el auto de 1612) y además les fijó un salario de 2 reales diarios, reafirmando la decisión de Alfaro. Esta medida favorecía claramente a los caciques, sus comunidades y encomenderos.

El cabildo de Jujuy, apeló la resolución de la audiencia. Aquí nuevamente, fue Martín de Ledesma Valderrama quien realizó la presentación pero esta vez en nombre del cabildo. En ella, se reconocía la posible existencia de intereses contrapuestos, dentro de este cuerpo entre los encomenderos y los vecinos que no lo eran. Finalmente, la audiencia determinó que se debían cumplir las ordenanzas, pero en compensación mantuvo el pago de los 2 reales como jornal, a lo largo del siglo XVII. ${ }^{29}$

A partir de ese momento, la mita de plaza de la ciudad de San Salvador de Jujuy no conoció nuevas reglamentaciones. Los contingentes se conformaron con la sexta parte de los tributarios encomendados en la jurisdicción. Las únicas modificaciones fueron las que ajustaban el total de

$27 \mathrm{El}$ argumento era cierto dado que en la actualidad, la distancia entre Humahuaca y la ciudad de Jujuy es de $126 \mathrm{~km}$ aproximadamente y entre Casabindo y Jujuy más de $220 \mathrm{~km}$.

28 ANB ec ad, 1769- 8, 33-33 v.

29 ANB ec ad, 1768- 8, 44. 
mitayos a los cambios demográficos de las encomiendas. ${ }^{30}$ Sin embargo, entre la normativa y la práctica existía una distancia. En varios momentos al cabildo de Jujuy le resultó dificultoso mantener la provisión de mitayos por diferentes motivos.

\section{«Enterando» la mita. Caciques y alcaldes de mita}

Siguiendo el modelo toledano, Alfaro había dispuesto —en su auto transitorio- que el reclutamiento de la mita estuviera bajo la jurisdicción de un alcalde mayor, dividiendo en dos figuras distintas la responsabilidad de la entrega completa del contingente de mitayos y su distribución en San Salvador de Jujuy. De la primera tarea, debía responsabilizarse el alcalde mayor de mita y de la segunda, el alcalde ordinario:

su merced dejara nombrado alcalde maior aparte que mire por dichos indios el qual ha de tener cargo y obligación de enterar el indio que faltare y a el se le han de pedir y no al encomendero aunque se huia y la repartición la han de hacer los Alcaldes ordinarios con la asistencia de la justicia maior y no se pueda dar indios de mita sino a vecinos propio que asista y tenga casa poblada y chacra y asistiendo en la dicha ciudad y esto se de a entender a los indios principales para que en el mes de mayo a primero tenga aparejadas la dicha mita. ${ }^{31}$

Sobre el alcalde de mita recaía la responsabilidad de «enterar» la misma ya que Alfaro eximió a los encomenderos expresamente de esta obligación. Por su parte, a los caciques también se les exigía la tarea de garantizar que los mitayos de su pueblo estuviesen preparados para que el alcalde mayor de mita los sumara al contingente de turno. Mientras que los alcaldes ordinarios debían efectuar el reparto de los mismos en la ciudad.

El auto de Alfaro no especificaba quien debía ejercer el cargo de alcalde mayor. El cabildo de Jujuy delegó esta función en los caciques de la región designándolos como alcaldes de mita. Posiblemente, los funcionarios del cabildo de Jujuy tuvieron en cuenta el modelo toledano de la mita minera que, en Potosí, sumaba la estructura estatal con la jerarquía de auto-

30 Sabemos que en 1635, el cabildo mandó realizar un empadronamiento general de acuerdo a las ordenanzas de Alfaro. También se realizaron recuentos generales en la visita del gobernador Acosta y Padilla en 1644, en la del gobernador José Garro en 1678 y por mandato de los gobernadores Peredo en 1671 y Argandoña en 1688. ATJ 1635-124; ATJ 1681-560; ATJ 1671-452, 26 v; AHJ 1689 XXIII-2, 234; AGI Charcas 26, R 16, N 118.

31 ANB 1692 Min- 62-7, $20 \mathrm{v}$. 
ridades indígenas a partir de la creación de las capitanías y los alcaldes de mita.

Desde 1618, se encuentra registrada la elección anual del encargado de la mita, tarea que recayó en algunos de los jefes étnicos más importantes de la zona. Ellos fueron elegidos como alcaldes hasta aproximadamente 1635, y la ejercieron preferentemente los caciques de Quebrada y Puna, y eventualmente sus hijos o alguna persona cercana (cuadro . $^{\circ} 3$ ). La práctica del mismo implicaba también la jurisdicción criminal sobre la población mitaya, ya que los alcaldes de mita portaban vara. No sabemos, si el desempeño en esta función produjo modificaciones o encumbramiento del cacique de un pueblo sobre otro. Resulta significativo que sólo en una oportunidad uno de ellos perteneciente a una de las encomiendas del Valle de Jujuy — que eran las más pequeñas— hubiese ejercido el cargo.

\section{CUADRO N. ${ }^{\circ} 3$}

\section{ALCALDES DE MITA DE LA JURISDICCIÓN DE SAN SALVADOR DE JUJUY AÑO 1618-1635}

\begin{tabular}{lll} 
Año & \multicolumn{1}{c}{ Alcalde de mita } & \multicolumn{1}{c}{ Procedencia } \\
1618 & Don Felipe & Cacique de Yala \\
1619 & Don Francisco Cuyracho & Cacique de Purmamarca \\
1620 & Don Marcos Tinta & Cacique de Casabindo \\
1621 & Don Francisco Viltipoco & Cacique de Tilcara \\
1624 & Don Andrés Choque & Cacique principal de Omaguaca \\
1624 & Don Andrés Choque & Cacique de Omaguaca \\
1625 & Pedro Casado & Indio Principal de Omaguaca \\
1626 & Don Andrés Choque & Cacique de Omaguaca \\
1627 & D Francisco Viltipoco & Cacique de Tilcara \\
1629 & D Pedro Auracayte & Principal de Casabindo \\
1630 & Francisco Viltipoco & Tilcara? \\
1633 & Juan & Hijo legítimo de Don Francisco Caranche \\
& & cacique de Purmamarca \\
1634 & Francisco Chapor & Hijo legítimo de Francisco Viltipoco \\
1635 & Don Francisco Vilte & Principal de Tilcara \\
\end{tabular}

Fuentes: AHJ, 1619 XXI-2-2:47; AHJ 1620 XXIII-1; AHJ 1622 XXIII- 1: 90, AHJ 1624 XXIII-1: 138; AHJ, 1624 XXIII-1:199; AHJ 1625 XXIII-1: 200; AHJ 1625 XXIII-1:214; AHJ 1626 XXIII-1:224; AHJ 1627 XXIII,-1:35v; AHJ 1635 XXIII-3:395 v; AHJ 1635 XXIII-3:417; AHJ 1629 XXI-1:80; AHJ 1631 XXI-1:128; AHJ 1633XXI-1:156; AHJ 1634XXI-1:182; AHJ 1635 XXI- 3- 3; ATJ -56: 3. 
Entre 1634 y 1636, el cabildo no pudo regularizar los envíos de mita a causa de la negativa a trasladarse a la ciudad de los mitayos de la Puna y de Ocloyas. El cabildo aprovechó esta coyuntura para desplazar a los caciques. En 1636, al año siguiente en que se deja de elegir a los alcaldes de mita, el procurador se quejaba de la falta de indios en el segundo turno de la mita, ya que muchos mitayos huían. Para las autoridades, el sistema no funcionaba correctamente porque los caciques no viajaban controlando el contingente y evitando las fugas. ${ }^{32}$

\section{Repartiendo la mita de plaza. Alcaldes ordinarios, vecinos e instituciones}

Una vez que el contingente mitayo llegaba a Jujuy, nos preguntamos ¿cómo se realizaron los repartos?, ¿quiénes fueron los principales beneficiarios del trabajo mitayo?, ¿a qué tarea se destinaba la mita de plaza? La Ordenanza 49 establecía:

que los yndios que ansi vienen de mita la mitad de ellos los rrepartan un alcalde y rregidor en cada lunes a las personas que mas bien les paresciere y la otra mitad se alquilen con quien ellos quisieran. ${ }^{33}$

Esta era una de las mayores aspiraciones de los vecinos sin encomiendas, ya que a través de la libre contratación podían acceder a mano de obra para llevar adelante distintos emprendimientos. En un contexto de necesidad debido al desarrollo de actividades productivas - como la agricultura (tanto para el mercado local u orientada a la venta de estos productos en las minas cercanas), la ganadería, la minería, el arreo de ganado en pie o los fletes de mercancías - contar con el aporte de los mitayos podía ser importante. Si bien desde la primera reglamentación de la mita de plaza, el interés de las autoridades se centraba en dotar de trabajadores a los habitantes - para evitar el despoblamiento de la ciudad—, esta necesidad también entraba en pugna con la de las instituciones. El cabildo también precisaba de trabajadores para las obras públicas o para mantener servicios tales como la reparación de edificios, caminos y puentes (vitales, ya que Jujuy estaba ubicada en

32 ATJ 1636-133, 20

33 Levillier, 1918, 311. 
la ruta que unía la gobernación de Tucumán con las zonas mineras), la limpieza de las acequias o el matadero y el abasto de carne.

En 1658 el traslado de un reparto mitayo nos permite conocer las formas en que se realizaba y a la vez, conocer el destino de la mita en Jujuy. Se trata de la copia de una memoria sobre la adjudicación del primer turno de mita, efectuada por el capitán Pablo Bernárdez de Ovando, alcalde ordinario de Jujuy y reciente encomendero de Casabindo y Cochinoca. ${ }^{34}$ En ese momento, se adjudicaron 54 mitayos en total. Del mismo 15 indios fueron asignados a instituciones o para funciones precisas de la ciudad (por ejemplo: la iglesia matriz, el cura rector, los conventos de San Francisco y La Merced, el alcalde de indios, el alcalde de aguas, el matadero y la cárcel). Los 39 restantes se distribuyeron entre particulares; 19 se compartían entre dos vecinos, alternando una semana cada uno. Resulta muy significativo que la mayor parte de la mano de obra mitaya se asignara a individuos antes que a instituciones o a servicios públicos (anexo n. $\left.{ }^{\circ} 1\right)$. En el reparto que se realizaba por cuadra, los primeros beneficiarios consignados eran algunos vecinos principales que no tenían encomiendas. Tras ellos, se enumeraban a otros menos encumbrados como la entrega de 9 mitayos a mujeres, 5 de las cuales eran viudas.

Entre los beneficiados encontramos a algunos como Alejandro de Urrutia, Thomas de la Guerra, Cristóbal de Ovando, Juan de Adaro, Francisco Salcedo o Juan Gaytan que poseían algunas tierras en las cercanías de Jujuy y tenían diferentes tipos de participación en el cabildo. Por ejemplo, el padre de Juan Gaytan había intervenido en la apelación contra la normativa de Alfaro en 1613, posteriormente se casó en segundas nupcias con Isabel de Ayala (heredera de la encomienda de Purmamarca) pero a la muerte de su mujer perdió el acceso a los tributos, la mano de obra de esta encomienda y sus hijos sólo heredaron dos chacras en Palpalá.

Con Juan de Ferreyra pasaba algo parecido. Ligado por matrimonio con la hija del encomendero de Yala, Alonso de Tobar, él no tenía derechos a la encomienda. Los restantes tenían ganado, eran labradores en pequeñas propiedades, arrieros o solían trabajar para otros vecinos. ${ }^{35}$ Sólo en un caso, el beneficiado era encomendero. Se cumplía de esta manera el objetivo principal de los gobernadores de Tucumán al establecer los primeros repar-

34 ANB, 1692 Min 62-7, 50-3

35 ATJ 1638-174, 28-31; ATJ 1673-501; ATJ 1680- 560; ATJ1673- 497; ATJ 1680-576; ATJ 1642- 236, 34-5; ATJ 1642- 236, 40; ATJ 1643- 242, 488; ATJ 1643- 249, 30; ATJ 1644-251, 22.; ATJ, 1640-26; ATJ 1646.-265, 34; ATJ1647-271; ATJ 1647- 271, entre otros. 
tos de mita como era dotar de mano de obra a los vecinos que no poseían encomienda. Este objetivo primaba inclusive sobre la necesidad de asignar mitayos para obras públicas.

\section{La disputa de la mita. Caciques, encomenderos, mineros y autoridades}

Por poco que pareciera, obtener el servicio de un solo mitayo (inclusive compartido) era una ayuda para la construcción o reparación de casas, labores agrícolas, guarda de ganado o inclusive en la arriería (a pesar de la prohibición). De no contar con este beneficio muchos de ellos se veían obligados a contratar mano de obra — compuesta de indios forasteros o indios de encomiendas locales - que resultaba más costosa que el salario de un mitayo. ${ }^{36} \mathrm{Si}$ se cumplían las ordenanzas de Alfaro, la retribución de ellos era de dos reales diarios, así un vecino debía pagar 28 pesos por turno más la comida. La cifra surge de calcular la suma de 2 reales diarios por los 4 meses completos. La reglamentación de Alfaro y de los gobernadores no especificaba si se asignaban días de descansos. De ser así, la cifra de pago sería menor. En cuanto a las retribuciones a indios contratados, es posible que en momentos de poca oferta de mano de obra, los particulares se vieran obligados a solventar salarios muy altos:

Que tengo hecho concierto con un indio del Perú llamado Martín para manejar junto con el las sementera como las cosechas con las que apenas me puedo sustentar ni puedo alcanzar con que se me de un mitayo por ser pocos los que ay y muchas las personas en quien sean despachados... y no podemos bibir los pobres que no tenemos encomiendas y teniendo librado mi sustento en el dicho yndio pagandole por tenerle seguro y contento mucho mas de los que se acostumbra de dar comumente a un indio, que son cien pesos en cada un año de que estoy debiendo la mitad del salario. ${ }^{37}$

36 Otro tipo de mano de obra utilizada en la jurisdicción era el trabajo esclavo, que tenía un alto costo para su adquisición y los cautivos que se obtenían de las entradas punitivas al Chaco y en las campañas militares a los valles Calchaquies. La participación en estas empresas militares tenía muchas veces el aliciente de obtener algunas piezas en calidad de cautivos. AHJ 1627 XXI-1, 32. Gonzales Rodríguez, ver: Sica, 2006; Sánchez-Sica, 1994.

37 ATJ 1642-232, 1.El subrayado es nuestro. Lorenzo de Chaves ya había apelado a los servicios de indios forasteros, ver: ATJ 1620-70, 3. En 1658, a su viuda se le asignó el trabajo de un mitayo compartido con otra. 
Si bien en este caso, los 100 pesos prometidos constituían un costo muy grande para la época, no conocemos la excepcionalidad del mismo. Aun así, la necesidad de mano de obra podía resultar acuciante en determinados momentos y en algunas actividades económicas. Debido a su escasez, los vecinos sin encomiendas presionaban por la libre contratación de indígenas encomendados y por la regular provisión de la mita de plaza. ${ }^{38} \mathrm{~A}$ lo largo del XVII se produjeron diversos conflictos en torno a la institución. Algunos de ellos, terminaron con largos pleitos en la audiencia de Charcas en los que se discutía sobre la aplicación de la normativa transitoria de Alfaro o de las ordenanzas definitivas; los conflictos con la jurisdicción de Salta sobre los mitayos de la Puna; los alcances de la autoridad del teniente de la Rinconada sobre la mita de Jujuy, o la posibilidad de entregar parte de los mitayos asignados a particulares por gobernadores o por la propia audiencia de Charcas. ${ }^{39}$ Además de los juicios, los mayores problemas que entorpecieron el funcionamiento del sistema de la mita fueron los levantamientos y huidas de los mitayos - especialmente en los traslados hacia la ciudad - favorecidos por los propios caciques según las autoridades. En otras ocasiones los propios encomenderos impedían la llegada de los mitayos. Durante el siglo XVII, las autoridades del cabildo debieron reiterar la necesidad de «enterar» la mita en por lo menos 6 ocasiones y enfrentar 3 levantamientos contra ella en diferentes regiones de la jurisdicción. ${ }^{40}$

Junto con estos litigios, en la realidad cotidiana de la ciudad la necesidad de disponer de mitayos enfrentaba a particulares y autoridades, o a representantes de algunas instituciones contra los alcaldes (quienes eran los encargados de la distribución de los trabajadores), y estas tensiones se resolvían con peleas y a gritos. Así, en 1641 el guardián del convento de San Francisco comprendió que no podía terminar la torre de la iglesia al no recibir mitayos en el reparto por tercer año consecutivo. Ofuscado llegó

38 AHJ 1620 XXII-1, 1620,f. 65-66; ATJ1644 -250, 1-1 v

39 Los gobernadores de Tucumán y la audiencia otorgaron cierta cantidad de mitayos a particulares para matanzas o laboreo de minas dentro de la jurisdicción o zonas vecinas. El caso más extremo fue la concesión de 6 indígenas destinados a la mita de plaza que el gobernador Argandoña le dio a Pedro Martínez de Tejada y Ovando en 1688. La misma fue revocada unos años después por el Consejo de Indias cuando Martínez pidió confirmación de ella como si fuese una encomienda AGI, Charcas 111,n 7, 1692.

40 ANB, Min- 62-7, 1692, 18; ATJ 1601-12; ATJ 1602-12; ATJ 1612-38; AHJ, 1624- XXII1, 200; AHJ 1629 XXI- 1, 103; AHj 1629 XXI-1, 105; AHJ 1630 XXI- 1, 115;AHJ, 1630 XXI-1, 117; AHJ 1634 XXIII- 1; AHJ 1635 XXIII-1- 2; ATJ 1633-133; AHJ 1666 XXV- 2; AHJ 1686 XXIII- 2; AHJ 1692 XXIII- 2. 
hasta la casa del alcalde de primer voto y tras una fuerte discusión consiguió que el cabildo le otorgara, excepcionalmente, dos mitayos para concluir la obra. ${ }^{41}$

Sin embargo, una de las contiendas más intensas por el aprovechamiento de los mitayos tuvo lugar entre los mineros de la jurisdicción y zonas vecinas, el cabildo y los vecinos de Jujuy. En este caso, primaba el interés de la política global de la corona de fomentar la minería por encima de los intereses locales de una jurisdicción. Desde fines del siglo XVI, se desarrollaba un foco de explotación argentífera en el cerro del Espíritu Santo de Cochinoca y otro, en el cerro Pan de Azúcar, los dos situados en la Puna de Jujuy. También se exploraban y beneficiaban minas en la zona de Lipez y Chicha, en los límites de la jurisdicción de Jujuy. ${ }^{42}$ En ese momento, la dinámica del desarrollo de la actividad minera conspiraba contra la mita. En 1601, el cabildo de Jujuy se quejaba ante el gobernador de Tucumán sobre las dificultades de poner en vigencia el primer reparto establecido unos años antes, dado que la: «...orden no se guarda y dejan de venir los dichos indios para darlos a las minas y otras partes...». ${ }^{43}$

Hacia fines de la década de 1630, la actividad minera en la Puna de Jujuy se hallaba en expansión al sumarse nuevas zonas en explotación, mientras que en Lipez se desarrollaba la exploración de los ricos depósitos de minerales del Nuevo Mundo y crecían los beneficios de los yacimientos de Chichas, como los de Chocaya, Esmoraca, Tupiza, etc. ${ }^{44}$ Uno de los pro-

41 AHJ 1641 XXI- 1, 208.

42 «...En otras partes de este distrito se han descubierto algunas minas como son en la provincia de los Chichas y en los confines de Tucumán y otras que se llaman de Cochinoca las cuales prometen mucha riqueza y se van poblando de españoles que acuden a poblarlas y trabajar en ellas. En todo lo que podemos fuera de lo que es repartir indios que esta a cargo de vuestro virrey, procuramos favorecer y ayudar las dichas poblaciones...» 1601, La Plata, CGGV, 3346 citado en Palomeque, 2006.

43 ANB, Min- 62-7, 1692, 18.

44 Las riquezas mineras de Lipez y Chichas eran conocidas desde las últimas décadas del siglo $\mathrm{XVI}$. Las primeras prospecciones y aprovechamiento de algunas vetas superficiales se iniciaron en esa época. El desarrollo de la actividad minera en Chichas comienza en los primeros años del siglo XVII con la puesta en marcha de las minas de Tupiza (1602), Esmoraca (1606), Tatasi (1612) Chocaya (1633). En 1646, existían en Chichas 18 asientos de minas: Chocara, Tatasi, San Vicente, San Francisco, Chorolque, Monserrate, Tasna, Choroma, Chocaya la vieja, Nuestra Señora del Rosario de la Nueva Mancera, Chilca, Los Serrillos, Esmoraca, Santa Isabel, El Bonete, San Cristóbal, La Trinidad y San Antonio junto con un importante número de ingenios. El desarrollo de las explotaciones de Lipes, también databa de finales del siglo XVI, pero el apogeo de la zona de San Antonio del Nuevo Mundo se dio entre las décadas de 1640 al 70. En la Puna de Jujuy también se desarrollaron emprendimientos mineros durante el siglo XVII, en la zona de Cochinoca y Rinconada. Albeck-Palomeque, 2009; ANB, 1604-123, 21-23v, ANB, ALPCAh 1606-538; Bakewell, 1988, 45; ANB, ALP CACh 1640-7, 390-392; ANB, 1634 Min 131/4; ATJ 1648- 270, 5. 
blemas frecuentes en estas minas eran las reiteradas inundaciones de sus socavones y la falta de mano de obra. La audiencia de Charcas, que desde comienzos del siglo XVII conocía las posibilidades y expectativas de esas explotaciones, decidió apoyarlas asegurando la provisión de trabajadores. En 1639, el presidente de la audiencia de Charcas demandó a los cabildos de Jujuy y de Salta la entrega de cien tributarios de sus encomiendas para ayudar en el desagüe de las minas de Chocaya. En el cabildo dudaron en cumplir la orden - contra la cual se había apelado - por los perjuicios que acarreaba respecto de la provisión de la mita. La medida quedó sin efecto debido a las presentaciones hechas por las autoridades locales. ${ }^{45}$

La intención de dotar de hombres para la explotación de las minas de Chichas continúo en los años siguientes. Pablo Espinosa, uno de los mayores empresarios mineros de la región, intentó obtener mitayos regulares - por diferentes medios- para sus emprendimientos de Chichas. Para ello, Don Pablo apelaba no sólo a su larga trayectoria (más de 2 décadas) como poseedor de extensas vetas y algunos ingenios sino también a las relaciones surgidas de su casamiento con Ana María Velazco y Patiño. En 1646, Espinosa pidió al virrey del Perú, el marqués de Mancera, que se le otorgara el sistema de mita similar al que funcionaba en Potosí para las minas e ingenio de Nuestra Señora del Rosario y Nueva Mancera. ${ }^{46}$ La misma debían cumplirla los pueblos de Calcha y Santiago de Cotagaita de la provincia de Chichas. Sin embargo, esta medida fue revocada porque ellos aportaban mitayos a los ingenios de Potosí. Por esa razón, el virrey reasignó 30 indios de mita, provenientes de Atacama, Casabindo, Cochinoca, Lipez, Omaguaca, Tilcara y Sococha. Nuevamente el cabildo, los encomenderos y los caciques de Jujuy se opusieron a la medida. Los argumentos esgrimidos fueron varios. El primero era la inexperiencia que tenían los indios de la jurisdicción. También se objetaba el sistema de endeudamien-

45 ATJ 1639-166. La decisión del presidente de la real Audiencia estaba precedida por una serie de informes sobre la explotación y rendimiento de las minas de Chocaya. En los mismos se estimaba que en tres años, la mina de Nueva Chocaya podía tener una alta productividad: «... en ese paraje descubrio la mayor riqueza que se ha visto en ningun otro asiento de mina midiendo de la veta vara y media de ancho de un tal tan rico que cada cajon de el (se entiende 50 quintales de metal) se sacaban $15,20,30$, piñas de mas de 40 marcos cada uno de plata... de que se habra sacado de aquel asiento diez millones y Don Alonso 700.000 \$ \{su descubridor\}...». ANB, 1637-13, 145v.-146.

46 Pablo Espinosa se dedicaba a la explotación minera desde fines de la década de 1610. Había acompañado a Alonso de Ortega, uno de los primeros en aprovechar las riquezas mineras de Chichas. Estaba casado con Ana María Velasco y Patiño quien estaba emparentada con el virrey de Nueva España y Perú Luis de Velasco y Castilla y con el gobernador de Tucumán Juan Ramírez de Velazco, ANB, ALP CACh 1637- 13, 146-146v, ATJ 1648-269; ATJ 1648-270. 
to que utilizaban los empresarios mineros al pagar los salarios en coca, vinos y otros productos en lugar de dinero. Pero sobre todo los perjuicios para las comunidades que ya aportaban la sexta parte de sus tributarios a la mita de plaza de Jujuy y el menoscabo que recibían los vecinos de Jujuy. Las protestas surtieron efectos a pesar de las potenciales ganancias que auguraba la explotación de las minas de Espinosa, la audiencia de Charcas terminó por revocar la medida.

Contemporáneamente al embate de los mineros de Chichas, los caciques y las comunidades de la Puna también debieron hacer frente a las pretensiones de los mineros de Rinconada. En este caso, las demandas de mano de obra se entremezclaban con un conflicto jurisdiccional con la vecina ciudad de Salta. En su petición, un grupo de empresarios mineros de Rinconada sostenía que la Puna era parte de su jurisdicción. ${ }^{47}$ Aseguraban que los mitayos de Casabindo y Cochinoca debían ser enviados a Salta y no a Jujuy. También pedían la libre contratación de los tributarios de las encomiendas de Casabindo, Cochinoca y Omaguaca sin que se los impidieran los curas, encomendero o autoridades del cabildo de Jujuy. En este caso, fueron los caciques de Casabindo y Cochinoca quienes lograron revertir la orden de la Audiencia de entregar 30 mitayos a los mineros. Debido a su presentación, este número se redujo a 6 trabajadores, aunque no tenemos constancia de su cumplimiento efectivo. ${ }^{48}$

\section{Consideraciones finales}

A pesar de lo restringido que podía ser el alcance de la mita de plaza de Jujuy en relación a la movilización y el impacto que provocaba la mita minera en Potosí, no dejaba de tener vital importancia para los implicados en la jurisdicción y regiones colindantes.

47 La ciudad de Salta, fundada en 1582, había perdido una parte considerable de su jurisdicción original debido a la fundación de la ciudad de San Salvador de Jujuy. De esta pérdida, el territorio más disputado fueron las tierras altas de la Puna que comprendía zonas con potenciales riquezas en minerales y una relativamente importante población indígena. El pedido de los mineros de Rinconada, que se reconocían como vecinos de Salta, en 1646 estaba precedido por varios conflictos entre ambos cabildos. Dichas disputas se desataban cuando los alcaldes ordinarios de Salta, entraban a la Puna tratando de ejercer su autoridad o de desviar la entrega de los mitayos de Casabindo y Cochinoca hacia la ciudad de Salta Ver: AHJ 1625-XXII-1, AHJ 1629-XXI-1, 103; AHJ 1636 XXIII- , 467; AHJ 1636 XXIII- 1, 475; ATJ 1636-133, 17.

48 ANB 1646 Min 62-3. 
La provisión de mitayos significaba contar con mano de obra para las obras públicas, pero sobre todo para quienes no habían accedido a una encomienda. Su importancia se ve en la continua acción del cabildo por establecer y asegurar la cuota anual de trabajadores, acción que se concretaba a partir de los pedidos realizados por los procuradores a los distintos gobernadores de Tucumán y al visitador Alfaro a fin de establecer el funcionamiento de la institución. Las Ordenanzas de 1612, establecieron definitivamente el sistema de mita de plaza para la gobernación del Tucumán. Sin embargo, estas ordenanzas mostraban algunas contradicciones respecto a lo dispuesto provisoriamente por Alfaro en 1611 cuando se hallaba en Jujuy. Estas discrepancias en torno al número de mitayos y el jornal, fueron objeto de litigios que enfrentaba a caciques y encomenderos contra los vecinos sin encomienda. En ellos tuvieron activa participación los caciques y fueron zanjados por la audiencia de Charcas, mediante una solución que conformara a los dos sectores en pugna. A partir de ese momento, la mita de plaza de San Salvador de Jujuy no conoció nuevas reglamentaciones. Los contingentes se conformaron con la sexta parte de los tributarios encomendados en la jurisdicción.

Establecida la institución, los alcaldes de primer voto debieron asumir la responsabilidad del reparto de los contingentes en dos turnos anuales, según llegaban a la ciudad. En el reparto de 1658, se advierte que la mayor parte de los trabajadores se destinaban al servicio de particulares (tal como había sido el objetivo de su primera implementación) por sobre las instituciones o servicios públicos. La competencia de esta mano de obra resulta significativa al observar que una importante cantidad de vecinos - especialmente los más desfavorecidos como las mujeres viudas- aceptaban compartir el trabajo de los mitayos semana de por medio con otro beneficiario. El reparto de 1658, muestra también que no se cumplía totalmente lo dispuesto en las ordenanzas. En teoría, los alcaldes sólo debían adjudicar la mitad del contingente cada semana y la otra mitad podía contratarse libremente. En la práctica, se asignaba la totalidad de los mitayos desapareciendo las posibilidades de alquilar un mitayo para cualquiera que no hubiese entrado en el reparto.

Si bien a veces la distribución provocaba algunos conflictos y altercados, estos resultaban de poca monta frente a los problemas que ocasionaba el viaje y el entero de la mita en los meses de marzo y agosto. Alfaro había instituido la creación del cargo de alcalde mayor de mita, como el funcionario responsable de la entrega y traslado de los mitayos desde sus pueblos 
a Jujuy. Durante casi 20 años el nombramiento recayó en los caciques principales de la jurisdicción. Pero en la década del 30, ante los problemas que surgían, el cabildo comenzó a nombrar personas consideradas de confianza para transportar a los mitayos. Estas personas ya no ostentaban el cargo de alcalde de mita. En esta situación problemática, el cabildo responsabilizaba a los caciques por no poder completar la mita y también por las huidas que protagonizaban algunos mitayos.

El peso de la mita se advierte en los conflictos emergentes del proceso de institucionalización como también en su funcionamiento. La mano de obra mitaya era disputada alternativamente por los habitantes sin encomienda, los encomenderos, los caciques y comunidades, otras ciudades y otros sectores como el minero. Para los primeros el acceder al trabajo de un mitayo era importante en el desarrollo de sus actividades y resultaba más barato que contratar mano de obra libre. Sin embargo, la mayor demanda que los vecinos, autoridades y las propias comunidades debieron enfrentar fue la de los mineros que podían esgrimir el apoyo de oidores e incluso virreyes ante quienes se invocaba el interés político y económico de la corona.

Los caciques de la región desempeñaron un activo papel tratando de rebajar el peso de la mita sobre sus pueblos, de mejorar las condiciones de trabajo y la retribución de los afectados por ellos, oponiéndose a las pretensiones de los mineros o favoreciendo huidas y levantamientos. Sobre ellos recayó durante un tiempo el cumpliendo de las funciones como alcaldes de mita, hasta que las dificultades y conflictos terminaron por extinguir el cargo.

\section{Referencias}

AGI: Archivo General de Indias.

AGN: Archivo General de la Nación (Argentina).

ANB: Archivo Nacional de Bolivia (Sucre).

CGGV: Colección Gaspar García Viñas.

AHJ: Archivo Histórico de Jujuy.

ATJ: Archivo de Tribunales de Jujuy. 


\section{Bibliografía}

Abecia, V.: Mitayos en Potosí en una economía sumergida, Barcelona, Ed. Hurope, 1988.

Albeck, María y Palomeque, Silvia: «Ocupación española de las tierras indígenas de la puna y "raya del Tucumán" durante el temprano período colonial», Memoria Americana, 17-2, Buenos Aires, 2009, 173-212.

Assadourian, Carlos Sempat: «La producción de la mercancía dinero en la formación del mercado interno colonial. El caso del espacio peruano, siglo XVI», Florescano, E, (comp.), Ensayos sobre el desarrollo económico en México y América Latina (1500-1975), México, F.C.E., 1979, 223-292.

Assadourian, Carlos Sempat: El sistema de la economía colonial. Mercado interno, regiones y espacio económico, Lima, I.E.P, 1982.

Assadourian, Carlos Sempat: «La crisis demográfica del siglo XVI y la transición del tawantinsuyu al sistema mercantil colonial», en Sánchez Albornoz, Nicolás (ed.), Población y mano de obra en América Latina, Madrid, Alianza, 1985.

Assadourian, Carlos Sempat: «Acerca del cambio en la naturaleza del dominio sobre las Indias: la mita minera del Virrey Toledo. Documentos de 15981571», Anuario de Estudios Americanos, 46, Sevilla, 1989, 3-68.

Bakewell, Peter: Miners of The Red Mountain, Albuquerque, Nuevo México, University Press, 1984.

Boixados, Roxana y Zanolli, Carlos (eds.): La visita de Luján de Vargas a las encomiendas de La Rioja y Jujuy (16693-1694). Estudios preliminares y fuentes. Editorial Universidad Nacional de Quilmes, Buenos Aires, 2003.

Cobb, G.: Potosí y Huancavelica. Bases económicas: 1545-1640, La Paz, Academia Boliviana de la Historia, 1977.

Coole, J.: The Potosi Mita. 1573-1700. Compulsory Indian labor in the Andes, California, Stanford, 1985.

Doucet, Gastón: «Los autos del visitador Don Antonio Martínez Luján de Vargas», Revista de Historia del Derecho, 8, Buenos Aires, 1980, 123-154.

Doucet, Gastón: «Introducción al estudio de la visita del Oidor Don Antonio Martínez Luján de Vargas a las encomiendas de indios del Tucumán», Boletín del Instituto de Historia Argentina y Americana Dr. Emilio Ravignani, 26, Buenos Aires, 1980, 205-246.

Doucet, Gastón: «Notas sobre el yanaconazgo en el Tucuman», Revista de Investigaciones Juridicas, 6, 6, Mexico, 1982, 263-300.

Gil García, Francisco: «Los Lipez y la mita de Potosí: considerando la situación de un grupo étnico surandino dentro del entramado colonial (siglos XVIXVII)», en Gutiérrez Escudero, Antonio y Laviana Cuetos, María Luisa (coords.), Estudios sobre América: siglos XVI-XX, Sevilla, Asociación Española de Americanistas, 2005, 691-711. 
González Casanovas, Ignacio: Las dudas de la corona: La política de repartimientos para la minería de Potosí (1680-1732), Biblioteca de Historia de América, 20, Madrid, 2000.

González Rodríguez, Adolfo: La encomienda en Tucumán, Sevilla, Universidad de Sevilla, 1984.

Levillier, Roberto: Correspondencia de la ciudad de Buenos Aires con los reyes de España. Documentos del Archivo de Indias, Madrid, Biblioteca del Congreso de la Nación Argentina, 1918.

Lorandi, Ana María: «El servicio personal como agente de desestructuración en el Tucumán colonial», Revista Andina, 6-1, Cusco, Centro Bartolomé de las Casas, 1988, 135-173.

Lorandi, Ana María: «Mestizaje interétnico en el Noroeste argentino», en Tamoeda \& Millones, 500 años de mestizaje interétnico, Osaka, National Museum of Ethnology, 1992, 133-167.

Palomeque, Silvia y Tedesco, S.: «Padrón de los indios de Casabindo y Cochinoca 1654. Transcripción», Manuscrito, 1999.

Palomeque, Silvia: «El mundo indígena (siglos XVI-XVIII)», en Tandeter, Enrique (dir.), Nueva Historia Argentina. La sociedad colonial, Buenos Aires, ed. Sudamericana, 2000, 87-144.

Palomeque, Silvia: «Historia de los señores étnicos de Casabindo y Cochinoca», Revista Andes, 17, Salta, UNSa, 2006, 139-194.

Pucci, Roberto: «El tamaño de la población aborigen del Tucumán en la época de la conquista: balance de un problema y propuesta de nueva estimación», Población y Sociedad, 5, San Miguel de Tucumán, 1995, 239-270.

Ravignani, E.: «Las poblaciones de las regiones del río de La Plata y Tucumán en la segunda mitad del siglo XVII», Actas y Trabajos Científicos del XXV Congreso Internacional de Americanistas, T. II, Buenos Aires, 1934, 295-305.

Rowe, J.: «The Incas under Spanish colonial institutions», Hispanic American Historical Review, 37-2, 1957, 155-99.

Rubio Durán, Francisco: Tierra y ocupación en el área surandina, Sevilla, Ed. Aconcagua, 1998.

Ruiz Rivera, Julián B.: Encomienda y mita en Nueva Granada en el siglo XVII, Sevilla, Escuela de Estudios Hispano-Americanos, 1975.

Sánchez Albornoz, Nicolás: «La mita de Lima: magnitud y procedencia», Revista Histórica, 12/2, Lima, 1988,193-210.

Sánchez, Sandra y Sica, Gabriela: «Por ser gente de otra ley... Tobas, mocovies y ojotaes reducidos en el valle de Jujuy. Prácticas y discursos. Siglo XVII y XVIII», Journal de la Societé des Americanistes, 83, París, 1997, 59-82.

Sica, Gabriela: Del pucara al pueblo de indios. La sociedad indígena colonial en Jujuy, Gobernación de Tucumán, siglo XVII, Tesis doctoral, Universidad de Sevilla, 2006. 
Tandeter, Enrique: Coacción y mercado: la minería de la plata en el Potosí colonial, 1692-1826, Cuzco, Centro de Estudios Andinos «Bartolomé de Las Casas», 1992.

Vergara, Miguel Ángel: Compendio de la historia de Jujuy, San Salvador de Jujuy, Imprenta de la Provincia de Jujuy, 1961.

Whigtman, A.M.: Indigenous Migration and Social Changes. The forasteros of Cuzco 1520-1720, Durham, Duke University Press, 1990.

Zanolli, Carlos: Tierra, encomienda e identidad: Omaguaca (1540-1638), Buenos Aires, Sociedad Argentina de Antropología, 2005.

Zulawsky, Ann: «Forasteros y yanaconas: la mano de obra de un centro minero en el siglo XVII», Harris, Larson y Tandeter (comps.), La participación indígena en los mercados surandinos. Estrategias y reproducción social. Siglos XVI a XX, La Paz, Ceres, 1987, 159-92. 